\title{
O discurso da insegurança: os imigrantes perigosos - uma etnografia no Bairro Veronetta (Verona, Itália, 2015-2016)
}

\author{
The discourse of insecurity: the dangerous immigrants \\ - ethnography in Veronetta (Verona, Italy, 2015-2016)
}

Fabiane Cristina Albuquerque*

\author{
Palavras-chave: \\ Imigração \\ Representação \\ Insegurança
}

Keywords

Immigration

Representation

Insecurity

\begin{abstract}
Resumo: Atualmente, a maneira mais difusa de representar a imigração é aquela da metáfora de uma "invasão", criada por diversas estruturas de poder (mídia, governos, partidos políticos). Este artigo contribui para a reflexão sobre a recepção desse discurso pelos próprios imigrantes em uma realidade delimitada, o bairro Veronetta (na cidade de Verona, Itália), escolhido entre os anos de 2015 e 2016 como campo de pesquisa para uma etnografia ao longo de quatro meses. O objetivo era entender se os imigrantes desse bairro incorporavam ou não a representação dominante sobre eles próprios ligada ao problema da segurança, da ameaça à ordem, do "roubo" dos postos de trabalho e, ainda, se viam ou não a si mesmos nessa representação, e quais as resultantes formas de resistência ou os fatores que influenciavam na reprodução de tais discursos. A escolha do campo em questão se deu através da experiência da pesquisadora como imigrante na cidade e por frequentar Veronetta que, segundo dados da Prefeitura de Verona, tem o maior índice de imigrantes por habitantes autóctones, carregando o estigma de ser um bairro "de má fama", "perigoso" e "inseguro".
\end{abstract}

\begin{abstract}
Today, the most diffuse way to represent immigration is that of the metaphor of an "invasion", created by various power structures (media, governments, political parties). The article contributes to the reflection on the reception of this discourse by the immigrants themselves in a delimited reality, the neighborhood Veronetta (in the city of Verona, Italy), chosen between the years of 2015 and 2016 as a field of ethnography research along four months. The aim was to understand whether or not the immigrants in this neighborhood incorporated the dominant representation of themselves in connection with the problem of security, the threat to order and the "stealing" of jobs, and whether or not they saw themselves in that representation, and which are the resulting forms of resistance or the factors that influenced the reproduction of such discourses. The choice of the field in question occurred through the researcher's experience as an immigrant in the city and by frequenting Veronetta who, according to Verona city hall, has the highest number of immigrants by native inhabitants, bearing the stigma of being a "bad neighborhood", "dangerous" and "unsafe".
\end{abstract}

Recebido em 02 de abril de 2018. Aprovado em 30 de julho de 2018.

\section{Introdução}

Esse artigo deriva da minha pesquisa de mestrado, cuja dissertação traz o título de "Imigração e Insegurança: representações aprisionam? Uma etnografia no bairro Veronetta". Entre outros aspectos, o termo “insegurança” é utilizado como metáfora das condições atuais de vida no mundo globalizado, como em Beck (2001), quando fala de "sociedade de risco" e Giddens (1990, 2002) de "cultura de risco" inerente à modernidade. Já outros utilizam "incerteza” e "perigo" como características

\footnotetext{
* Graduada em Ciências Sociais pela Universidade Federal de Goiás (UFG), mestra em Filosofia pela Università di Verona (Itália), mestra em Comunicação Intercultural pela Università di Verona (Itália), mestra em Sociologia pela Universidade Estadual de Campinas (Unicamp), doutoranda em Sociologia pela Unicamp com o tema “O Corpo do Imigrante". Ligada ao departamento de Ciências Humanas e Filosofia da Unicamp e membro do grupo de pesquisa sobre gênero PAGU, da Unicamp.
} 
de uma contemporaneidade que incide nos aspectos mais íntimos da vida e do caráter dos indivíduos, a exemplo de Bauman (2005) e Sennett (2009). Sabendo que tais termos não são sinônimos e que os autores os entendem de forma diferente, em linhas gerais o objetivo em meu mestrado foi investigar o contexto para a difusão de um crescente sentimento de insegurança e entender o desenrolar de uma abordagem securitária das sociedades, presente, sobretudo, nas leis, nos discursos e nas práticas sociais que criminalizam alguns grupos, com destaque para o caso do imigrante.

Interessa discutir no presente artigo como a imigração se tornou o canalizador e a representação social dominante, em muitas sociedades, desse tipo de sentimento de insegurança, enquanto muitos imigrantes são construídos individual e coletivamente por meio dessa força - a exemplo do que se encontra atualmente, no contexto socioeconômico, político e cultural do bairro Veronetta (escolhido como campo de pesquisa para uma etnografia ao longo de quatro meses). Para Lourenço e Lisboa (1992), o sentimento de insegurança é a expressão de uma representação social do meio, em que lógicas culturais, de identidade e circunstâncias desempenham um papel importante no modo de representar a insegurança. Logo, e como salienta Frias (2008), não é algo dado, mas construído. Por seu lado, a Escola de Copenhague fornece uma importante reflexão sobre o que seus estudiosos chamam de "teoria da securitização"2, a partir do entendimento de que a ameaça à segurança é também uma construção social. Dentre outras coisas, isso implica a "impossibilidade de avaliar plenamente se as ameaças são reais ou não"; mais ainda, não existiriam problemas de segurança, mas sim problemas que foram "securitizados" (LEONARD, 2010, p. 235). A securitização resulta, como visto, centrada no discurso e nas práticas que criam determinado problema como questão de segurança - neste caso, os imigrantes.

A cidade escolhida para a pesquisa foi Verona, pois apresenta o maior número de imigrantes da Região Veneto, sendo Verona uma das cidades mais ricas da Itália que, paradoxalmente, é considerada "fechada" para imigrante e para os italianos do sul. Situada no norte do país, fica entre as cidades de Milão e Veneza, e é conhecida como a cidade de "Romeu e Julieta" (onde se passa a peça homônima de Shakespeare entre 1594 e 1596). O bairro Veronetta, campo da presente pesquisa, embora irrelevante dentro da ordem econômica mundial e "invisível" diante de outras cidades globais e bairros de maior fama e presença de imigrantes, possui, no entanto, uma realidade interessante para se perceber a "recepção" de um discurso securitário sobre a imigração, bem como as transformações advindas desse discurso em relação às mudanças no espaço físico e nas relações sociais, seja entre imigrantes, seja entre os autóctones.

Uma das características que mais destacam Veronetta dos demais bairros habitados por imigrantes nas grandes cidades italianas é que ele se encontra a apenas um quilômetro (cerca de dez minutos a pé) do centro da cidade, bem como de suas principais atrações turísticas, como a Arena de Verona e a Casa de Julieta. Portanto, não é um bairro periférico - no sentido de "periferia" como entendido nas metrópoles, geralmente distante e com difícil acesso aos pontos centrais, com precária infraestrutura etc. O que separa Veronetta do centro histórico de Verona, por exemplo, é o Rio Adige, o principal da cidade, sendo o acesso ao bairro feito por mais de uma das grandes pontes que cruzam o rio (a principal delas é San Fermo). Assim, vivi em Veronetta durante quatro meses, entre os anos de 2015 e 2016, onde foram realizadas, ao todo, 37 entrevistas semiestruturadas com imigrantes de diferentes nacionalidades (brasileiros, cingaleses, mexicanos, albaneses, romenos, indianos, chineses, marroquinos, entre outros), além de também ter sido interessante perceber as falas sobre a própria cidade e a região italiana.

As principais nacionalidades presentes em Veronetta são: Sri Lanka (25\%), Romênia (9,9\%), Brasil (6,2\%), Albânia (6,2\%), Nigéria (5,9\%), Marrocos (5,2\%) e Gana (4,3\%). Em 2006, os imigrantes do bairro consistiam em $19,7 \%$ de sua população, ou seja, 2.090 imigrantes sob um total de $10.411 .^{3} \mathrm{O}$ bairro é, ainda, caracterizado pela degradação física dos prédios e das ruas, o 
que muitos relacionam tanto ao "problema" dos imigrantes que se encontram pelas ruas como ao descaso das políticas urbanas locais existentes. Veronetta também foi um bairro que atraiu muitos italianos do sul da Itália ${ }^{4}$ nos anos 1960, tendo, na verdade, passado de "Terronetta" 5 para "Negronetta" (BRIATA, 2011, p. 4). Uma das ruas que frequentei era habitada por famílias provenientes do sul, mas que estão ali há mais de 30 anos.

A entrevista qualitativa tem como objetivo adentrar na visão do sujeito estudado e, para que a voz predominante seja realmente aquela do entrevistado, tal instrumento precisa ser flexível e adaptável às suas diversas personalidades, podendo "mudar de sujeito a sujeito" (CORBETTA, 1999, p. 407). As entrevistas feitas se caracterizam como semiestruturas ${ }^{6}$ através de um questionário organizado com nove perguntas, cuja flexibilidade foi de suma importância: não sendo o italiano a língua materna da pesquisadora, nem dos imigrantes, palavras que a alguns eram conhecidas e familiares, a outros não eram.

Tabela 1: Imigrantes entrevistados por sexo e nacionalidade

\begin{tabular}{lcc}
\hline & Imigrantes entrevistados & \\
\hline País de origem & Masculino & Feminino \\
\hline Marrocos & 1 & 1 \\
Brasil & 7 & 2 \\
Sri Lanka & 1 & 1 \\
Índia & 0 & 1 \\
Nigéria & 1 & 0 \\
Gana & 1 (refugiado) & 1 \\
Albânia & 1 & 1 \\
Romênia & 3 & 3 \\
China & 0 & 1 \\
Peru & 0 & 1 \\
México & 1 & 1 \\
Guiné Bissau & 1 & 1 \\
Senegal & 1 & 0 \\
Japão & 1 & 0 \\
Macedônia & 1 & 0 \\
Kosovo & 1 & 0 \\
Mali & 1 (refugiado) & 0 \\
Total (homens e mulheres) & 23 & 14 \\
\hline Total de imigrantes & & 37 \\
\hline
\end{tabular}

Fonte: Elaborada pela autora (2018).

\section{O discurso dos imigrantes sobre a insegurança}

Durante as entrevistas, percebi que muitos imigrantes se referiam aos "marginais" que viviam em determinados pontos do bairro como causadores de insegurança, e outros indicavam algumas ruas como "zona de degrado". Assim, percebi que precisava chegar a esses imigrantes estigmatizados, ao mesmo tempo em que tomaria maior consciência, através desta experiência, de que meu corpo de mulher e latina, sozinha em locais predominantemente masculinos, era um problema.

Nas zonas indicadas como local de perigo, logo conheci alguns brasileiros, a exemplo de trabalhadores de construção civil como Jerry, um rapaz de 28 anos oriundo da região sul do Brasil, que me explicou a vida do bairro e descreveu que o local era como o "Brooklin de Verona". Por outro lado, confirmou que se tratava de um local seguro, embora eu tivesse de tomar cuidado somente com "alguns marroquinos". A alusão ao "marroquino" como fator de perigo também foi recorrente em outras entrevistas, visto que referiu esse povo como causador de insegurança no bairro (de modo que estabelecer contato com um desses imigrantes se tornou um objetivo importante para minha pesquisa). E, quando conheci o brasileiro Márcio, em um primeiro contato, eu mesma pensei que ele fosse um imigrante oriundo de Marrocos devido às características físicas: escuro de pele e cabelos crespos. De fato, Márcio demonstrou bastante sofrimento pela rotina de ser confundido com um "marroquino" - no sentido pejorativo da acepção dessa palavra no contexto local. Daí, quando o questionei se já havia sofrido algum tipo de preconceito, respondeu prontamente: "Todos os dias. Olha só a minha cara de marroquino".

Percebi, então, a amplitude deste termo: "marroquino", ali, era usado para se referir a qualquer pessoa de cor escura e cabelo crespo (tendencialmente com implicações desfavoráveis), a exemplo de alguns imigrantes provenientes da Tunísia que conheci, e que eram chamados dessa mesma forma por outros moradores do bairro. Quando encontrei realmente um marroquino nesta 
zona estigmatizada apontado por um brasileiro como sendo dessa nacionalidade, eu me aproximei e perguntei se ele poderia me ensinar a fazer o chá marroquino, pois eu estava voltando da loja do senhor Mohamed naquele momento com as mãos cheias de hortelã. Com uma visível satisfação, ele me indicou a quantidade que eu deveria colocar na água. Animada com o primeiro contato perguntei se ele era marroquino, o que fez com que sua fisionomia mudasse por completo: "Mais ou menos" foi sua resposta. Então, percebi que havia cometido um grande erro e perdido a ocasião de falar com ele, pois a palavra "marroquino" traz, em si, uma carga muito negativa para alguns deles, sendo muitas vezes usada como forma de ofensa.

Uma senhora da Romênia, Oxana ${ }^{7}$, dona de casa a procura de trabalho e formada em direito em seu país, revelou durante a entrevista:

Eu penso que são muitos aqueles que chegam aqui e fazem com que eles [italianos] tenham medo. [...] Eu respeito todas as nações, mas as pessoas têm medo, isso prejudica também os outros e muitos dizem "é a crença deles". Não. Eles não têm educação, não têm uma educação certa. Tem mulçumanos que se comportam bem como os cristãos, mas é preciso antes de tudo se dar o respeito e respeitar [...] Os italianos são bons, querem tratar bem a todos, mas entenderam que nem todos podem ser tratados como humanos. Daí eles pedem comida e depois começam a atrapalhar [...] brasileiros, romenos, moldavos são nações trabalhadoras. [...] As nações que não trabalham (fala em baixa voz e olha ao redor), os marroquinos. Eles falam demais, não gosto. Os chineses são trabalhadores, mas são fechados, trabalham fechados.

Pela sua fala, vê-se que a ideia que Oxana faz de "perigo" e "ameaça" está ligada a certos tipos de comportamentos, como "pedir esmolas", "falar demais", fato confirmado em outras entrevistas com imigrantes. É este perigo que, para Quasoli (2001), se baseia em uma ideia de "ordem", e o simples fato de um imigrante não jogar uma latinha no cesto de lixo é um sinal de "incivilidade", e mesmo de "ameaça”.
O depoimento de Caique 9 , um jovem brasileiro que vive na Itália há quase dez anos, entre outros aspectos, repõe algo do abandono do espaço público por parte do Estado, colocado como um problema de imigração.

A maioria é do Marrocos. Eles saem já do país deles com a cabeça errada. Eles são mulçumanos, né? Não podem fumar, não podem beber, chega aqui eles fazem pior, né? É o dinheiro fácil que levam eles, nem fácil é. Eles ficam aí o dia inteiro vendendo (se refere a substâncias ilícitas) por 20,30 euros por dia. E falam que não têm trabalho. Pra mim, é mentira. Se você levanta cedo e vai procurar, você acha. Tem oportunidade. Não é que todo mundo vai te bater a porta na cara. Um dia alguém te abre. Eles têm essa cabeça, e nem gosto de sair com eles. Eu tenho só um amigo do Marrocos. Ele tem outra cabeça. Ele é mulçumano, reza cinco vezes por dia, não come carne de porco, não bebe, não fuma, mas é um cara respeitador total. Eu conheci ele na escola. Colega de classe. Esses aqui são todos bandidos, né? [...] Mas se bem que não vejo maldade neles de roubar as pessoas [...] Eu fecho à 1 da madrugada, sozinho, dinheiro do caixa na mão. Mas não tenho medo. Aqui não é Brasil. O cara lá já te aponta uma arma na cara e é dois segundos. Aqui o máximo que fazem é te ameaçar com uma faca. [...] Eu conheço bem a zona. Sempre estudei aqui. Antes não era assim. Começou nos anos 2000 quando os estrangeiros começaram a entrar na Europa, Itália. Aí começaram a vir pra cá, se instalaram todos aqui. O aluguel é mais barato aqui. Aqui tá perto do centro.

De um lado, o jovem brasileiro afirma que "não se sente seguro de noite"; por outro, diz não ver "maldade" nos marroquinos, ao ser visto fechando seu bar de madrugada, portando dinheiro consigo, e não ter problema com isso. Essa mecanicidade em reproduzir o discurso dominante apareceu várias vezes nas falas dos entrevistados. Mas, quando falavam da própria experiência, referiam nunca ter tido problemas com "aqueles" que eles apontam como "perigo" e "ameaça". Parece existir, então, uma grande diferença entre o discurso e a prática, uma vez que, para alguns imigrantes, a negação 
de que existe racismo, preconceito ou qualquer forma de discriminação (ou que são estereotipados) também é um modo de dizer que estão integrados, que os italianos gostam deles e os aceitam, se livrando, assim, da "culpa" que muitos pensam existir na presença dos próprios imigrantes ali, devido, justamente, ao peso de tais representações negativas. Uma senhora, Alina ${ }^{10}$, da Romênia, que tem um comércio de alimentos no bairro, afirmou: "Eu nunca tive problemas aqui. Precisa se comportar bem pra viver aqui. Estou aqui há 12 anos e meu marido há 30. Nunca tive problema com meu filho na escola. Conheço muitos italianos. Eles trabalham e cumprem suas obrigações".

A necessidade de encontrar uma figura que encarnasse essa representação da insegurança esteve presente em diversos discursos. Sales (1999) verificou que, no caso de brasileiros nos Estados Unidos, a alusão a uma figura que encarnasse a "alteridade" e a quem fosse, assim, transferido todo o mal da imigração era comum: devido à desigualdade social no Brasil, para muitos imigrantes brasileiros de classe média, igualar-se com outros brasileiros era algo não habitual e isso fez com que muitos daqueles entrevistados pela autora apontassem um "outro" inferior, criando, assim, um mito ou o "outro imaginário" que prejudicava a própria imagem dos brasileiros. No entanto, não parecia ser esse o caso dos brasileiros entrevistados em Veronetta; as mesmas nacionalidades apontadas por eles como "problema", ou como "bons" e "maus", são idênticas àquelas indicadas pela própria sociedade italiana. Além do mais, a percepção da própria condição de ser brasileiro também foi apreendida no ambiente no qual vivem, experiência essa que, para a maioria, era positiva. Ainda de acordo com o brasileiro Jerry:

Eu moro aqui há dez anos, no bairro. Antes não era assim. Tinha poucos marroquinos, africanos. A gente se reunia na Rua San Nazarro, porque tem uma internet de um brasileiro chamado Lázaro. Lá se reunia uns 40 brasileiros. A polícia chegava e mandava todo mundo embora. Mas a gente voltava (risos). Era o ponto para procurar trabalho. Um fala para o outro. Eu fui parado várias vezes, mas veem que sou brasileiro $e$ me deixam. Os brasileiros são mais aceitos que os marroquinos. Se tem três marroquinos e entram cinco brasileiros, eles dão trabalho para os brasileiros. Eles gostam da gente. Já tive experiência de racismo. Tem italiano que diz que a gente vem pra roubar o trabalho deles.

Outro elemento interessante apontado pelos imigrantes é essa comparação entre um "agora" e um "antes". Muitos afirmavam que "agora está melhor", pois havia sido feito esse tipo de "limpeza" que vários apontaram como sendo a expulsão de muitos imigrantes indesejáveis do bairro. Outros, ao contrário, expressaram certo saudosismo com relação ao passado ("antes") que, para alguns, significava cerca de 20 anos atrás, e mesmo não tendo vivido propriamente nesse período ali no bairro, aludem a uma época boa devido à menor presença de imigrantes. Para alguns, a percepção da diminuição do número de imigrantes no bairro está ligada à ação do Estado através da polícia e à "limpeza" operada por ela. Antony, atendente em um Centro de Imigração de Verona ${ }^{11}$, no entanto, disse que muitos deixaram o bairro e o país por causa da crise econômica de 2008.

Como visto, e conforme também se verificou na afirmação anterior de Caique (na Itália desde 2007) de que há uns 20 ou 30 anos "o bairro não era assim", algumas falas remetem a um tempo imaginário que justifica a presente frustração pela atual fama do bairro. Hiroki, japonês há muitos anos na Itália, conclui que "[...] a impressão que tive com a cidade de Verona 40 anos atrás era de uma cidade tranquila. Agora com os imigrantes, os veroneses não estão preparados para recebê-los da maneira certa". Já para outros, esse "tempo melhor" é certamente o agora. Para Mohamed, o bairro já foi pior, mas melhorou com a "limpeza". Para Margarida $^{12}$, a realidade "melhorou muito. Estão mais abertos. As pessoas entendem mais e aceitam os estrangeiros".

\section{Reprodução do discurso dominante, incorporação das nacionalidades “perigosas” e o marroquino como problema}

Como é sabido, algumas nacionalidades foram construídas de forma estigmatizadas. Para 
o sociólogo estadunidense Goffman (2004), o termo "estigma" é um aspecto negativo dado pela sociedade que marca um indivíduo ou um grupo. Embora o autor não trabalhe com as mudanças nas sociedades e como os "estigmas" podem mudar, sabe-se que essa estigmatização não é estática, tendo sempre sofrido mudanças no decorrer da história. Entre outros, ele aponta como exemplo o caso dos deficientes físicos, para quem, ao longo dos anos, houve uma grande mudança em relação ao modo de serem vistos pelas diversas sociedades, que não mais os isolaram ou excluíram como outrora.

Já através da indústria da "islamofobia", Basso e Perocco (2003) afirmam que opera um "Racismo de Estado" que criminaliza a população muçulmana, ação extensiva, ainda, à criminalização dos ciganos, de grupos do leste europeu, dos árabes em geral e dos negros (que sofrem uma "opressão a mais"). Existiria entre nacionalidades e raças, além disso, certa "hierarquização" (BASSO; PEROCCO, 2003 , p. 37), pois a visão europeia dos povos do Terceiro Mundo seria de que esses são "povos criança", "predadores", "violentos, sanguinários", "forçados a serem como são devido à própria cultura e religião" (BASSO, 2010, p. 15). Segundo dois depoimentos de brasileiros:

Os italianos não gostam de romenos, eslavos, marroquinos, aqueles que a gente sabe que aprontam mais. Tem muita delinquência aqui. Dos africanos nunca ouvi nada, nem do pessoal do Sri Lanka, chineses... Isso tá ligado ao modo de vida deles. Não são pessoas confiáveis. Eu me sinto segura aqui. Não saio sozinha à noite, eu tenho medo de grupos. Grupos de estrangeiros, de italianos não. Principalmente jovens. Mas Verona é ainda segura. (Margarida).

Ah, tem gente que nem estudou e diz "ah, o estrangeiro vem roubar trabalho", mas eles não entendem que é culpa da "roubalheira" dos politicos deles, por isso está assim. Eles são muito racistas com chineses, porque os chineses estão comprando tudo, geral. Muitos italianos fecharam as portas, restaurantes, bares. Eles falam dos chineses "essa merda", "essa raça é igual cogumelo, cresce em qualquer lugar". Isso eu escuto muito.
Também dos indianos e do Bangladesh eles falam muito mal. Não é que eles generalizam, mas falam que é a maior parte. Falam muito dos refugiados. Agora que estão chegando da Síria, África. Muitos amigos meus são contra completamente, falam: "Eu afundaria o barco que eles estão", "Pô, esses caras vêm pra cá, já estamos na merda. Vão roubar nosso trabalhos", "o governo ajuda eles e não nos ajuda, que somos italianos". É isso que você escuta aqui. (Caique).

Em uma entrevista de grupo com três moradores de rua, percebi que eles tentavam distanciar deles a noção de "perigo", afirmando a todo o momento que são "homens de bem" ou "tranquilos" (como repetiram várias vezes):

[P.] As pessoas nos tratam bem. Eu te digo uma coisa. Se eu for no Brasil ou você for na Romênia e trata bem as pessoas, te tratam bem; se trata mal, as pessoas te tratam mal. Aqui é a mesma coisa, elas te tratam bem, se trata mal, te tratam mal. Chega a polícia "Ciao" (o policial diz) e "Ciao" (como ele responde). "Estejam tranquilos rapazes" (como dizo policial).

[B.] Pegam o documento. Não somos gente que faz bagunça, perigosos. Não somos desses, não. Que roubam, não, não. Não somos perigosos.

[P.] As pessoas não têm medo de nós, não, não. Os italianos nos conhecem todos. Esse rapaz lá (aponta para um deles) está aqui há 15 anos, todos nos conhecem. Antes trabalhávamos, pagávamos aluguel. Já tem uns dois meses que não trabalhamos.

Ao perguntar se eram ciganos, responderam em tom de defesa, em coro: "não, não tem nada a ver com nós!”. Na sequência, um deles disse:

[P.] Sabe como distinguir um cigano? É simples, vou te falar. Aqueles que estão sempre pedindo esmolas com os cachorros na cidade são ciganos, não romenos. Os que pedem são ciganos. Os que estão estacionando carro não. Esses não são ciganos, fazem pra viver. Na Praça Erbe [centro da cidade], têm muitos que fazem assim [sinal de pedir com as mãos]. 
Perguntei se era perigoso falar com eles, e responderam: "[P.] Não, não, pode falar. Fica atenta! Têm ciganos que tem coração. Não são todos iguais. Mas, olha sempre o bolso, o celular". Ao terminar a entrevista, um deles pegou na minha mão e a beijou, e os outros dois fizeram o mesmo gesto. O primeiro deles, então, disse que era "um respeito pela mulher" e acrescentou: "Se fossemos ciganos, fazendo assim" - pegou minha mão para beijar de novo - "você já não teria mais", e mostra o meu anel. E outro deles logo confirmou: "é verdade! Te digo a verdade".

Segundo Buttler (2004), a situação dos mulçumanos e árabes piorou bastante depois dos atentados de 11 de setembro nos EUA, perseguidos como "inimigos" do Ocidente e gerando efeitos devastadores nas condições de vida desses grupos. Soma-se a isso a formação do Estado Islâmico, os atentados de Charlie Hebdo e Bataclan Concert Hall em Paris em 2015, e do caso recente da violência contra mulheres alemãs na noite de ano novo em 2016, por parte de rapazes "árabes" e "norte-africanos", que fazem difundir o estereótipo da "incivilidade" e do "terrorismo".

\section{Considerações finais}

Como unidade menor e um espaço "ideal" para se entender a reprodução de um discurso sobre o espaço social e seus moradores que afeta as interações sociais com os imigrantes, percebese que o bairro Veronetta já era motivo de uma imagem negativa com a presença de italianos do sul, antes mesmo de o bairro ser definitivamente estigmatizado com a chegada "em massa" do imigrante. Este número crescente, entre outras coisas devido ao baixo custo dos aluguéis, como visto, passou a ser relacionado com a degradação da região, quando, na verdade, teria ocorrido um processo contrário, a saber: a "degradação" das moradias é que teria atraído os imigrantes. Não por acaso, porque não raramente um inquilino é quem aluga ali uma única cama, e não um quarto, uma casa ou apartamento. Portanto, são estas condições de moradia de Veronetta que primeiramente acabaram dificultando as relações sociais desses imigrantes (principalmente do sexo masculino) à condição de conviverem muito tempo nas ruas da cidade, especificamente neste bairro. Resulta daí serem apontados certos comportamentos (estar parado diante de locais, fumar e beber em grupos) como causa de insegurança, e as ruas com a maior concentração de imigrantes serem aquelas "mais perigosas". Como bem lembra Bertani (2006), alguns comportamentos de ordem moral e de ofensa ao decoro social se tornaram um problema de segurança pública, como consumir bebidas alcoólicas pela rua, permanecer em grupos até tarde da noite fora de casa, falar alto ou "atrapalhar" os demais moradores. Comportamentos "desordeiros" e "indecorosos" podem criar, também nesse caso, uma imagem do bairro como espaço degenerado.

Ao final, confirma-se que muitos dos imigrantes entrevistados internalizaram esse discurso sobre o próprio bairro onde vivem, ou seja, como um lugar "inseguro" e "perigoso". No entanto, durante as falas, percebeu-se uma grande contradição entre a experiência vivida e seu discurso, uma vez que muitos apontaram o bairro como local para ser evitado, principalmente em relação a outros grupos, enquanto, por outro lado, nenhum entrevistado afirmou haver sofrido algum tipo de ação violenta ou que, em algum momento, tivesse sido colocado sob ameaça.

\section{Notas}

1 A pesquisa de mestrado foi desenvolvida no Departamento de Sociologia da Unicamp sob orientação do Prof. Dr. Michel Nicolau Netto, e a dissertação foi apresentada em março de 2017.

2 A Escola de Copenhague, ao elaborar a "teoria da securitização", tem como principal representante o estudioso Ole Waver (LEONARD, 2010), para quem não existe um "problema de segurança", mas problemas que foram "securitizados". Daí a imigração estar sendo tratada como problema de segurança, sobretudo, pelos governos dos países centrais como Estados Unidos e membros da União Europeia.

3 Ver: Os dados mais recentes sobre a população do bairro (incluindo o percentual de imigrantes) são de 2006, e se encontram disponíveis no site da Prefeitura de Verona, no Departamento de Estatística: <https://www.comune. verona.it/media//_ComVR/Cdr/Statistica/Allegati/ recupero_gennaio_2008/Il_quartiere_Veronetta_2006. pdf>. Acesso em: 20 jan. 2016. 
4 Existe na Itália uma construção da região Norte em relação à região Sul de forma a representar esta última de forma pejorativa e preconceituosa. Diversos são os fatores que contribuíram para isso, e não iremos nos atear à história dessa construção, mas acenar para as principais teorias pseudocientíficas que contribuíram para a inferiorização da população do sul em relação ao norte. Uma delas está no pensamento de Cesare Lombroso que consolidou a ideia de que existem propensões ao crime por parte de algumas "raças", estando o sul da Itália incluído nessa sua teoria. Outra teoria aponta a diferença em termos de cultura e tem como um dos precursores o norte-americano Edward Banfied, que sustentava a ideia de que as famílias do sul pensavam somente no próprio núcleo familiar. A diferença econômica entre as regiões e a industrialização do Norte da Itália veio a corroborar essas ideias de superioridade e inferioridade entre a população das duas regiões.

5 Neologismo criado a partir das palavras "terrone" e "Veronetta". "Terrone" é um modo pejorativo para se referir aos italianos do sul.

6 No caso de "entrevistas semiestruturadas", Corbetta (1999, p. 421) diz que o questionário representa apenas uma pista ou um primeiro "arremesso", pois será a realidade que mostrará ao pesquisador a maneira de adaptar as perguntas e o modo de perguntar.

7 Nome fictício.

8 O termo "incivilidade" é usado aqui como o avesso de civilidade. Por "civilizado" podemos dizer, de acordo com Norbert Elias em O processo civilizador (1990), que é aquele que apreendeu os padrões ocidentais de conduta dado por tipos de comportamentos e ações no dia a dia, tais como a forma de comer, sentar, andar, falar, se dirigir às pessoas etc. Elias (1990) descreve ainda em seu livro que cuspir no chão ou arrotar na mesa eram permissivos antes do processo de civilização protagonizado pela Corte.

9 Brasileiro, 20 anos, desde 2007 na Itália.

10 Nome fictício.

11 Este Centro de Imigração, conforme se encontra escrito na porta do local, atende imigrantes que precisam de orientação quanto a documentos e trabalho. $\mathrm{O}$ atendente informou que o local é mantido por um advogado que trabalha pela causa da imigração, sendo gratuito todo o material fornecido aos imigrantes, como fotocópias de documentos e informações.

12 Brasileira, proveniente de Fortaleza, 50 anos, há 25 anos na Itália.

\section{Referências}

BASSO, Pietro. Tre temi chiavi del razzismo di stato. In: (Org.). Razzismo di Stato: Stati Uniti, Europa, Italia. Milano: FrancoAngeli, 2010.
.; PEROCCO, Fabio. Gli immigrati in

Europa. In: (Org.). Gli immigrati

in Europa: Disegualianza, Razzismo, Lotte. Milano: Franco Angeli, 2003.

BAUMAN, Zygmunt. Confiança e medo na cidade. Rio de Janeiro: Jorge Zahar, 2005.

BECK, Ulrich. La società del rischio.Verso una seconda modernità. Roma: Carocci, 2001.

BERTANI, Michele. Capitale sociale e reti informali in aree ad alta densità di immigrati: il quartiere di Veronetta". Dalla società civile al capitale sociale. A cura di Paola Di Nicola. Milano: Franco Angeli, 2006.

BRIATA, Paola. "Dall'immigrazione come risorsa alle risorse dei quartieri multietinici. Pianificazione e 'Città delle differenze"' (Paper for the Espanet Conference). In: Innovare il welfare. Percorsi di Trasformazioni in Italia e in Europa. Conferência Espanet. Milão, set./out. 2011. Disponível em: $<$ http://docplayer.it/9128050-Dall- immigrazionecome-risorsa-alle-risorse-dei-quartieri-multietnici. html>. Acesso em: 29 mar. 2016.

BUTTLER, Judith. Precarious life: The Powers of Mourning and violence. London: Verso, 2004.

ELIAS, Norbert. O processo civilizador. Formação do estado e civilização. vol. II. Tradução Ruy JUNOMANN. Rio de Janeiro: Jorge Zahar Editor, 1990.

FRIAS, Graça. A Construção Social do Sentimento de Insegurança em Portugal na Atualidade. SociNova, Lisboa, p. 1-14, 2008.

GIDDENS, Anthony. As consequências da Modernidade. São Paulo: Unesp, 1990.

Modernidade e Identidade. Rio de Janeiro: Zahar, 2002.

GOFFMAN, Erving. Estigma. Notas sobre a manipulação da identidade deteriorada. Tradução de Mathias Lambert. . Rio de Janeiro: Sabotagem, 2004. 
LEONARD, Sarah. EU border security and migration into the European Union: Frontex and securitization through practices. Journal of Contemporary European Research, v. 5, n. 3, p. 371-388, 2010.

LOURENÇO, Nelson LISBOA, Manuel. Representações da violência. Percepção social do grau, da frequência, das causas e das medidas para diminuir a violência em Portugal. Lisboa: Centro de estudos judiciários, 1992.

SALES, Teresa. Brasileiros longe de casa. São Paulo: Cortez, 1999.

SENNETT, Richard. A Corrosão do Caráter: consequências pessoais do trabalho no novo capitalismo. Rio de Janeiro: Editora Record, 2009. 